\title{
In-situ Observation of Intergranular Crack Nucleation in a Grain Boundary Controlled Austenitic Stainless Steel
}

\author{
S. Rahimi, D.L. Engelberg, J.A. Duff, T.J. Marrow \\ School of Materials, The University of Manchester,
}

Grosvenor Street, Manchester, M1 7HS, UK

\begin{abstract}
Grain Boundary Engineering (GBE) has been proposed to increase the lifetime performance of sensitised austenitic stainless steel in aggressive environments. Increased microstructure resistance is typically associated with higher fractions of twin $(\Sigma 3)$ grain boundaries, but there is uncertainty about the properties and role of other boundaries. In order to develop predictive models for stress corrosion crack nucleation, more information is required about how grain boundary crystallography and the orientations of the grain boundary plane and its surrounding grains affect crack development. Digital Image Correlation (DIC) combined with Electron Backscatter Diffraction (EBSD) has been used to characterise the microstructure and to observe, in-situ, the nucleation and propagation of short stress corrosion cracks in thermomechanically processed Type 304 stainless steel. The crack path and its growth rate have been determined, and are found to be influenced by the microstructure.
\end{abstract}

\section{Introduction}

Intergranular stress corrosion cracking (IGSCC) results from the combination of susceptible material, critical environment and sufficient mechanical driving force. It is a critical failure mechanism in some components of power generation plant (Scott 2000), where cracking of austenitic stainless steels can result from sensitisation of certain grain boundaries after heat treatment (such as post-weld stress relief) or fast neutron irradiation in nuclear plant. Sensitisation is a decrease in the local resistance to stress corrosion, to a degree that depends on the grain boundary structure (Bruemmer \& Was 1994; Zhou et al. 2001).

Grain boundary structure is commonly described using the coincidence site lattice (CSL) notation. This describes the orientation relationship between the crystal lattices of grains adjacent to the grain boundary, and is generally obtained using two dimensional electron backscatter diffraction (EBSD) techniques (Randle 1998). This 2D method provides no information on the actual grain boundary plane for most boundaries. Nonetheless, this description has been sufficient to enable the resistance to intergranular degradation of materials to be improved by grain boundary engineering (Palumbo et al. 1991; Lehockey et al. 2004). This is done typically by maximising the fraction of $\Sigma 3$ grain boundaries through thermo-mechanical processing. Increasing in number fraction of higher order twins $\left(\sum 9,27\right)$ is indicative of the twining process, as these are geometrically necessary features.

Three-dimensional in-situ observations of IGSCC, using sensitised type 302 austenitic stainless steel (Babout et al. 2006; Marrow et al. 2006) have provided evidence for crack bridging. Crack bridging was attributed to non-sensitised grain boundaries, whose development is associated with twinning. Models for this mechanism predict that the mechanical shielding effect of crack bridging directly influences the crack tip strain, and hence the propagation rate of short cracks. Grain boundary engineering to increase the proportion of sensitisation resistant boundaries is predicted to significantly increase the incubation period for crack nuclei, and thereby increase IGSCC resistance (Jivkov et al. 2006; Jivkov et al. 2007). 
Validation and further development of such IGSCC models requires observations of the threedimensional interaction between cracks and microstructure, and therefore full threedimensional characterisation of the microstructure itself. This work is in progress, using novel techniques for microstructure characterisation such as diffraction contrast tomography (Johnson et al. 2008; King et al. 2008; Ludwig et al. 2008), which allows direct observation of the grain boundary planes and grain orientations to be combined with in-situ observation of crack nucleation and growth. This method, however, is limited in terms of sample size and the range of microstructures that can be observed. Parallel investigations using twodimensional characterisation of microstructure and crack behaviour remain necessary.

Collection of crack growth statistics during IGSCC is experimentally complicated and only very limited data are available in the literature (Kamaya \& Haruna 2006; Nakano et al. 2007). Digital Image Correlation (DIC) allows full field strain data to be obtained throughout the deformation of a material via optical observations (Sutton et al. 1983). Such strain mapping can be used to observe crack nucleation (Joyce et al. 2008). DIC operates through the discretisation of an image into multiple interrogation windows that are correlated with the same area in following images. Displacement vectors can be obtained for the change in position of each interrogation window allowing strain distributions across the full image to be calculated (McKenna \& McGillis 2002). Theoretically, this allows measurements accurate to sub pixel displacements for samples that have a random, homogenous speckle pattern and where the only change in the image obtained is due to displacement (Quinta Da Fonseca et al. 2005). Conventionally, DIC has been carried out on materials deforming in air in response to an applied load. Observation of IGSCC in-situ and through a liquid environment using DIC is achievable however (Duff \& Marrow 2008), and is used in this investigation to assess, for the first time, the effects of microstructure modifications by thermo-mechanical processing on the crack nucleation behaviour in type 304 stainless steel.

\section{Experimental Details}

\section{Material and Thermo-Mechanical Processing:}

A type 304 Austenitic stainless steel plate was used with initial dimensions of $1 \mathrm{~m} \times 1 \mathrm{~m}$ x 13 $\mathrm{mm}(\mathrm{LxWxT})$. The chemical composition is given in Table 1, and the material was received in the mill-annealed condition. Sample blanks of $200 \mathrm{~mm}$ x $13 \mathrm{~mm}$ x $13 \mathrm{~mm}$ (LxWxT) were machined parallel to the rolling plane and with the length along the rolling direction. These blanks were then annealed at $1050^{\circ} \mathrm{C}$ for 2 hours in argon atmosphere and quenched in water. Two microstructures were considered, which will be referred to as Solution Annealed (SA) and Thermo-Mechanically Processed (TMP). The SA samples were sensitised at $650^{\circ} \mathrm{C}$ for 20 hours in argon. The TMP samples were cold deformed in tension to $20 \%$ strain with a tensile test machine (MTS Alliance RT/100) at a crosshead displacement of $2 \mathrm{~mm} /$ minute, using an extensometer with $15 \mathrm{~mm}$ gauge length to record strain. These TMP samples were then annealed at $950^{\circ} \mathrm{C}$ for 26 hours in argon, followed by the same sensitisation treatment as the SA material. The annealing treatment at $950^{\circ} \mathrm{C}$ was chosen to increase the fraction of $\Sigma 3$ grain boundaries through recrystallization, whilst maintaining a small grain size. The thermally treated SA and thermo-mechanically processed TMP blanks were then machined to final dimensions of $90 \mathrm{~mm} \times 7 \mathrm{~mm} \times 3 \mathrm{~mm}$ (LxWxT). The treatments of the samples are summarised in Table 2.

\section{Microstructure Characterisation}

Both microstructures were characterised using electron backscatter diffraction (EBSD). Samples were prepared by first grinding with Silicon Carbide ( $\mathrm{SiC}$ ) emery paper with grit size of $240,400,800$ and 1200 successively then polished via $6 \mu \mathrm{m}, 1 \mu \mathrm{m}$ and $1 / 4 \mu \mathrm{m}$ lubricated 
diamond paste to obtain a mirror finish free from scratches. Finally, the central regions were electro-polished at ambient temperature for approximately 5 minutes at $45 \mathrm{~V}$ in an electrolyte of $92 \%$ Acetic Acid - 8\% Perchloric Acid with a stainless steel cathode to remove between 10-20 $\mu \mathrm{m}$ from the mechanically polished surface.

EBSD maps were then collected from both specimens, within regions that were identified by microhardness indentations. An HKL-EBSD system with a low light CCD camera (Nordlys II), interfaced to the Philips XL-30 FEG-SEM was used for this assessment. Data were acquired using Channel 5 Flamenco HKL software in the beam scanning mode, using an accelerating voltage of $20 \mathrm{kV}$ and a $100 \mu \mathrm{m}$ aperture. The acquisition time was set to $60 \mathrm{~ms}$ per point, with at least 8 maps recorded and digitally stitched together over a total area of 2.5 $\mathrm{mm}^{2}$. Grain boundaries were divided into low $\Sigma$ CSL grain boundaries $(\Sigma \leq 29), \Sigma 3$ grain boundaries, higher order twins $(\Sigma 9, \Sigma 27)$, and low angle grain boundaries (LAGB or $\Sigma 1$ ). Both, the length fraction and also number fraction were extracted, using the Brandon criterion (Brandon 1966).

\section{Stress Corrosion Testing}

After obtaining the EBSD maps, the surfaces were electro-etched in same electrolyte at $13 \mathrm{~V}$ for approximately one minute until suitable and appropriate surface features were revealed for the DIC stage. Further details of the optimisation of surfaces for DIC are given elsewhere (Duff \& Marrow 2008). The test specimens were loaded in 3 point bending with a span of 90 $\mathrm{mm}$ and a fixed displacement (Figure 1). The nominal bending stress was calculated from the applied displacement and the corresponding elastic strain (ASTM 1999) and an elastic modulus of $200 \mathrm{GPa}$. Samples were coated with insulating lacquer apart from a $2 \mathrm{~mm} \times 2$ $\mathrm{mm}$ window. This corresponded to the region that had been previously mapped by EBSD and was identified by microhardness indentations. The loaded specimens were exposed to a test solution of $0.1 \mathrm{M}$ potassium tetrathionate $\left(\mathrm{K}_{2} \mathrm{~S}_{4} \mathrm{O}_{6}\right)$, with the $\mathrm{pH}$ adjusted to 2 by diluted sulphuric acid $\left(\mathrm{H}_{2} \mathrm{SO}_{4}\right)$. The test solution was in a borosilicate glass beaker, mounted on an Olympus-BH2 optical microscope (OM). Images of the sample surface were recorded through the test solution, using a Zeiss MRm digital camera with Axiograb software. To avoid effects from turbidity or fluid movement, 3 images, 10 seconds apart, were taken at each time interval and averaged. The objective was a x5 Olympus MS-Plane lens, with a field of view of approximately $2 \times 1.5 \mathrm{~mm}$. The time interval between observations was 5 minutes for the first two hours, and then at hourly or longer intervals for a total period of up to 35 hours.

\section{Digital Image Correlation (DIC) Analysis}

The images obtained during the stress corrosion tests were analysed by the LAVision DaVis Image Correlation software (version 7.2) to obtain two-dimensional strain maps. Cracks can be identified in the strain maps due to an effective strain that is the result of the in-plane surface displacement as the crack opens. This strain is not a real material property but rather a virtual strain caused by a discontinuity in the displacement vectors either side of the crack, i.e. the material on one side of the crack moves relative to the material on the other side of the crack. Differentiation of these displacements will then result in a strain. Individual cracks are therefore identified and labelled by grouping adjacent pixels with strains measured above a chosen threshold, selected to minimise noise from the strain data. The surface crack length and the maximum strain across the crack are obtained for each crack in every image throughout the course of the experiment. The maximum strain across crack is currently assumed to be representative of the surface crack opening displacement. Further details of this analysis has been introduced elsewhere (Duff \& Marrow 2008). 
The strain maps for the SA microstructure was obtained using a $32 \times 32$ pixel window with $25 \%$ overlap, whereas the TMP microstructure was analysed using a 64 x 64 pixel window with $50 \%$ overlap. The strain threshold for feature identification was $0.2 \%$ for the SA microstructure and $0.075 \%$ for the TMP microstructure. One pixel is $1.49 \mu \mathrm{m}$. Displacements were therefore measured on the surface at positions with grid spacing of $36 \mu \mathrm{m}$ for the SA material, and $48 \mu \mathrm{m}$ for the TMP microstructure.

\section{Results}

Characteristic EBSD maps for the two microstructures are shown in Figure 2 and data for the grain boundary character distributions are summarised in Table 3. The grain size has decreased due to the TMP process, indicating a microstructure conversion through recrystallisation. The hardness of the SA and TMP microstructures were $199 \pm 7 \mathrm{HV} 1$ and $156 \pm 10 \mathrm{HV}$, respectively. The microstructures of the SA and TMP material had similar number fractions of $\Sigma 3$ grain boundaries with, however, increased fractions of higher order twins $(\Sigma 9, \Sigma 27)$ after TMP. This indicates the onset of multiple twinning during the TMP process. The higher order twin grain boundary fraction in the TMP microstructure is less abundant than typically observed in GBE-processed Type 304 microstructures (Engelberg et al. 2008). The term grain boundary controlled, rather than grain boundary engineered, is therefore used for the TMP material.

Example images obtained by the in-situ experiments are shown in Figure 3. The nominal stresses applied to the test specimens were $220 \mathrm{MPa}$ and $250 \mathrm{MPa}$ for the SA and TMP microstructures respectively. Visual comparison of the surface under load at the start and end of the experiment shows no significant difference (Figure $3 a$ and $b$ ). However, image correlation to obtain the horizontal strain by differentiation of the displacement map shows the progressive nucleation and growth and coalescence of elongated strain features, perpendicular to the applied stress (Figure $3 \mathrm{c}$ to e). The surface of the sample was slightly repolished after the experiment, to reveal cracks developed during this assessment. All cracks were intergranular and a comparison between the cracks on the re-polished surface and strain features observed during the experiment provided good agreement (Figure 3f).

Similar observations were obtained for the TMP sample (Figure 4). The recorded strain features appear offset from the observed cracks due to the larger window size that was used for the image correlation in this case. The location of the calculated features is linked to the grid spacing from the DIC window size and overlap. This grid spacing also determines the uncertainty in the measurement of length of the features. A larger window size was required for the TMP sample to increase the resolution of the displacement measurements sufficiently to detect strain related features.

Comparison of the optical micrographs, EBSD maps and the image correlation strain maps confirm that the localised features in the strain maps are due to intergranular stress corrosion cracking (Figure 5 and Figure 6). Data for the development of these identified strain features or cracks with time are shown in Figure 7, indicating that nucleation and growth occurs more rapidly in the SA microstructure than in the TMP microstructure.

More detailed examination of the cracked grain boundaries, identified by the strain maps and compared with the EBSD maps, can be used to obtain the proportions of grain boundary character types along the crack path. Over 80 cracked boundaries were studied in each microstructure. The data are shown in Figure 8, for both SA and TMP microstructures, and are compared with the grain boundary populations for the bulk microstructure (Table 3 ). The data for the cracked boundaries are given in Table 4. A significantly lower proportion of $\Sigma 3$ boundaries were found along the crack path, in comparison to the population in the microstructure. The twin-related boundaries $(\Sigma 9, \Sigma 27)$ and low angle grain boundaries $(\Sigma 1)$ 
also tend to exhibit higher resistance. Although no low angle grain boundaries were found to crack in the SA material, this result may not be statistically significant as they were observed to crack in the TMP material. Therefore no boundary type, classified by the CSL description, is found to be immune to intergranular cracking.

\section{Discussion}

The yield strength $(0.2 \%$ proof stress $)$ for this plate of type 304 stainless steel in the solution annealed condition $\left(1050{ }^{\circ} \mathrm{C}\right.$ for 30 minutes) has been previously measured to be $210 \mathrm{MPa}$ (Engelberg 2006). The nominal stresses applied were $220 \mathrm{MPa}$ and $250 \mathrm{MPa}$ for the SA and TMP microstructures respectively, hence it can be expected that the surface of both samples was strained above yield. The actual stress will depend on the applied strain and the workhardening behaviour of the two microstructures, and this has not been measured. This could be done by x-ray diffraction, although the accuracy of the technique is such that an uncertainty of the order of 30 to $50 \mathrm{MPa}$ would be expected (Kuroda \& Marrow 2008). It is currently judged that the elastic stresses present in the exposed surface are similar in magnitude and are of the order of $250 \mathrm{MPa}$.

The image correlation in-situ observations of cracking show a significant difference in the rates of crack nucleation and growth for the two microstructures. Incubation time may be affected by the degree of sensitisation and also variations in the level of cold work. These have not been quantified yet, so no firm conclusion can be drawn as to whether incubation time is affected directly by the change in grain boundary character distribution from thermomechanical processing. Initiation sites (e.g. Figure 5c and Figure $6 \mathrm{~b}$ ) can be identified, and appear to be at triple-junctions with several random grain boundaries. However, it is not possible, at this stage, to infer any relationship between initiation and the local crystallographic environment of grains at the triple junction. A larger body of data should allow this, however, and this may be used to inform crystal plasticity approaches to the modelling of crack initiation, for example.

The rate of crack growth does appear to be affected by microstructure (Figure 7). The applied stress has not been measured, and is assumed to be similar for both samples. However, the observed difference in crack growth rates is consistent with the observation that cracking occurs preferentially along grain boundaries with no special CSL relationship (Figure 8), and that such boundaries are present in a higher proportion in the SA microstructure than the TMP microstructure. The cracks in the TMP microstructure also exhibit significant crack bridging (Figure 4d), which is apparent from the discontinuous nature of the cracks on the specimen surface. Such bridging has been predicted to retard crack growth rates (Jivkov et al. 2007), consequently crack growth would be expected to be slower in the TMP microstructure.

Correlations between crack paths and grain boundary character have been reported previously (Gertsman \& Bruemmer 2006). The CSL character is clearly an incomplete description of the resistance to cracking, since some $\Sigma 3$ and twin related boundaries, are observed to crack (Figure 8).. Such boundaries are likely to be incoherent and thus more susceptible to sensitisation (Zhou et al. 2001). Recent three-dimensional observations of crack/microstructure interactions (King et al. 2008) have shown that boundaries which have a character close to low (hkl) index planes are less susceptible to cracking. Such boundaries include coherent $\Sigma 3$ twins with a $\{111\}$ habit plane, but can also include low angle boundaries and other boundaries which have no apparent special CSL relationship. The proportion of such boundaries in the microstructure may be obtained by 5-parameter grain boundary plane analysis, using a statistical analysis of EBSD data (Kim et al. 2005). Work is now in progress to correlate such characterisation of microstructure with the development of stress corrosion 
crack nuclei, with the objective of developing improved microstructure resistance through thermo-mechanical processing.

\section{Conclusion}

In-situ, quantitative, observation of stress corrosion crack nucleation has been achieved using digital image correlation analysis of optical micrographs, collected during a stress corrosion cracking experiment. Under similar mechanical loading, the observed cracks have a tendency to propagate more slowly in a thermo-mechanically processed microstructure which has a refined grain size and increased fraction of low $\Sigma(\Sigma \leq 29)$ grain boundaries. This implies that grain boundary control may be used to improved stress corrosion cracking resistance. This new method of crack growth observation may thus be used to assess the effects of microstructure modification, such as grain boundary engineering or control, and provide data to support predictive models for component lifetime.

\section{References}

ASTM (1999) G 39: Standard practice for preparation and use of bent-beam stress-corrosion test specimens.

Babout, L., Marrow, T. J., Engelberg, D. \& Withers, P. J. (2006) X-ray microtomographic observation of intergranular stress corrosion cracking in sensitised austenitic stainless steel. Materials Science \& Technology 22, 9, 1068-1075.

Brandon, D. G. (1966) The structure of high-angle grain boundaries. Acta Metallurgica 14, 1479-1484.

Bruemmer, S. M. \& Was, G. S. (1994) Microstructural and microchemical mechanisms controlling intergranular stress corrosion cracking in light-water-reactor systems. Journal of Nuclear Materials 216, 348-363.

Duff, J. A. \& Marrow, T. J. (2008) In-situ observation of intergranular stress corrosion cracking, PVP2008 Pressure Vessels and Piping Conference. Chicago, Illinois,

Engelberg, D. L. (2006) Grain boundary engineering for intergranular stress corrosion resistance in austenitic stainless steel. Ph.D. Thesis, The University of Manchester.

Engelberg, D. L., Humphreys, F. J. \& Marrow, T. J. (2008) The influence of low-strain thermo-mechanical processing on grain boundary network characteristics in type 304 austenitic stainless steel. Journal of Microscopy 230, 3,

Gertsman, V. Y. \& Bruemmer, S. M. (2006) Study of grain boundary character along intergranular stress corrosion crack paths in austenitic alloys. Acta Materialia 49, 1589-1598.

Jivkov, A. P., Stevens, N. P. C. \& Marrow, T. J. (2007) Meso-scale mechanical model for intergranular stress corrosion cracking and implications for microstructure engineering. Journal of Pressure Vessels Technology Transactions of the ASME - in press -.

Jivkov, A. P., Stevens, N. P. C. \& Marrow, Z. J. (2006) A three-dimensional computational model for intergranular cracking. Computational Materials Science 38, 442-453.

Johnson, G., king, A., Honnicke, M. G., Marrow, T. J. \& Ludwig, W. (2008) X-ray diffraction contrast tomography: A novel technique for three-dimensional grain mapping of polycrystals. Ii. The combined case. Journal of Applied Crystallography 41, 310-318.

Joyce, M. R., Marrow, T. J., Mummery, P. \& Marsden, B. J. (2008) Observation of microstructure deformation and damage in nuclear graphite. Engineering Fracture Mechanics - in press -.

Kamaya, M. \& Haruna, T. (2006) Crack initiation model for sensitized 304 stainless steel $\mathrm{n}$ high temperature water. Corrosion Science 48, 9, 2442-2456.

Kim, C.-S., Hu, Y., Rohrer, G. S. \& Randle, V. (2005) Five-parameter grain boundary distribution in grain boundary engineered brass. Scripta Materialia 52, 633-637.

King, A., Johnson, G., Engelberg, D., Marrow, T. J. \& Ludwig, W. (2008) Observation of intergranular stress corrosion cracking in a grain mapped polycrystal. Science - submitted -,

Kuroda, M. \& Marrow, T. J. (2008) Preparation of fatigue specimens with controlled surface characteristics. Journal of Materials Processing Technology - in press -.

Lehockey, E. M., Brennenstuhl, A. M. \& Thompson, I. (2004) On the relationship between grain boundary connectivity, coincident site lattice boundaries, and intergranular stress corrosion cracking. Corrosion Science 46, 10, 2383-2404.

Ludwig, W., Schmidt, S., Lauridsen, E. M. \& Poulsen, H. F. (2008) X-ray diffraction contrast tomography: A novel technique for three-dimensional grain mapping of polycrystals. I. Direct beam case. Journal of Applied Crystallography 41, 302-309. 
Marrow, T. J., Babout, L., Jivkov, A., Wood, P., Engelberg, D., Stevens, N., Withers, P. J. \& Newman, R. C. (2006) Three dimensional observations and modelling of intergranular stress corrosion cracking in austenitic stainless steel. Journal of Nuclear Materials 352, 62-74.

McKenna, S. P. \& McGillis, W. R. (2002) Performance of digital image velocimetry processing techniques. Experiments in Fluids 32, 1, 106-115.

Nakano, J., Miwa, Y., Tsukada, T., Endo, S. \& Hide, K. (2007) In situ scc observation on neutron irradiated thermally-sensitized austenitic stainless steel. Journal of Nuclear Materials 367-370, 940-946.

Palumbo, G., King, P. J., Aust, K. T., Erb, U. \& Lichtenberger, P. C. (1991) Grain boundary design and control for intergranular stress-corrosion resistance. Scripta Metallurgica et Materialia 25, 1775-1780.

Quinta Da Fonseca, J., Mummery, P. M. \& Withers, P. J. (2005) Full-field strain mapping by optical correlation of micrographs acquired during deformation. Journal of Microscopy 218, 1, 9-21.

Randle, V. (1998) Overview no. 127 - the role of the grain boundary plane in cubic polycrystals. Acta Materialia $46,5,1459-1480$.

Scott, P. M. (2000) Stress corrosion cracking in pressurized water reactors - interpretation, modelling, and remedies. Corrosion 56, 771-782.

Sutton, M. A., Wolters, W. J., Peters, W. H., Ranson, W. F. \& McNeill, S. R. (1983) Determination of displacements using an improved digital correlation method. Imaging and Vision Computing 1, 3, 133-139.

Zhou, Y., Aust, K. T., Erb, U. \& Palumbo, G. (2001) Effects of grain boundary structure on carbide precipitation in 3041 stainless steel. Scripta Materialia 45, 1, 49-54. 


\section{Figure and Table Captions}

Figure 1: Experimental set-up for in-situ observation of stress corrosion cracking. The solution thickness above the sample was approximately $1 \mathrm{~mm}$.

Figure 2: Characteristic EBSD maps of the microstructures of (a) solution annealed, (b) thermomechanically processed microstructures. $\sum 3$ boundaries are represented in red lines, $\sum 9$ and 27 boundaries are green lines, low angle grain boundaries $\left(\sum 1\right)$ are white lines and random boundaries are black lines.

Figure 3: In-situ observation of stress corrosion crack nucleation in the solution annealed (SA) sample, a) original surface under load, b) final surface under load after 35 hours exposure, c) surface super-imposed strain map after 3 hours, d) after 16 hours, e) after 24 hours and f) strain map after 24 hours superposed on re-polished surface. The direction of the applied stress is horizontal.

Figure 4: In-situ observation of stress corrosion crack nucleation in the thermo-mechanically processed (TMP) sample, a) surface super-imposed strain map after 15 hours, b) after 25 hours, c) after 35 hours and d) strain map after 35 hours superposed on re-polished surface. The direction of the applied stress is horizontal.

Figure 5: Correlation between observations in the SA microstructure, a) optical image of an intergranular crack, b) the EBSD map of the same area of microstructure, c) the strain map obtained after 16 hours, d) strain map after 24 hours. In (b), (c) and (d) the $\sum 3$ boundaries are represented in red lines, $\sum 9$ and 27 boundaries are green lines, low angle grain boundaries $\left(\sum 1\right)$ are white lines and random boundaries are black lines.

Figure 6: Correlation between observations in the TMP microstructure, a) optical image of an intergranular crack, b) the EBSD map of the same area of microstructure accompanied with superimposed strain map after 15 hours, c) the strain map obtained after 25 hours, d) strain map after 35 hours. In (b), (c) and (d) the $\sum 3$ boundaries are represented in red lines, $\sum 9$ and 27 boundaries are green lines, low angle grain boundaries $\left(\sum 1\right)$ are white lines and random boundaries are black lines.Figure 7: Development of strain features observed during the experiment in solution annealed (SA) and Thermomechanically processed (TMP) microstructures. Time from the start of the experiment is shown.

Figure 8: The number fraction of cracked grain boundaries, compared with the average number fractions in the microstructure, a) SA microstructure, b) TMP microstructure. 
Table 1: Nominal composition of stainless steel 304, used in this study supplied by manufacture (wt.\%), .

Table 2: Summary of heat treatments applied to Solution Annealed (SA) and Thermo-mechanically Processed (TMP) microstructures.

Table 3: Summary of the grain boundary character data obtained by EBSD for the solution annealed (SA) and thermo-mechanically processed (TMP) microstructures. The range is the standard deviation from at least 8 individual maps.

Table 4: Summary of the characteristics of the cracked grain boundaries along the crack paths identified by DIC for the solution annealed (SA) and thermo-mechanically processed (TMP) microstructures. 


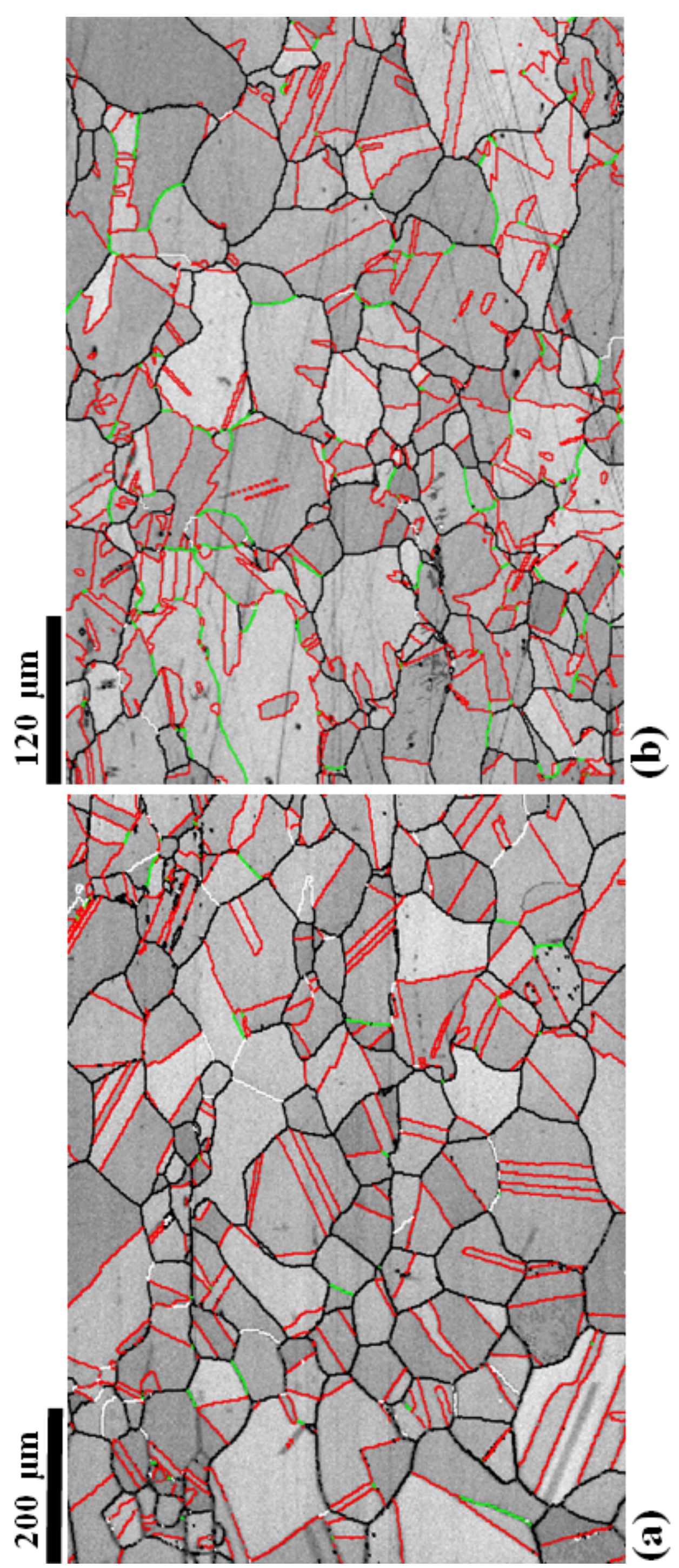




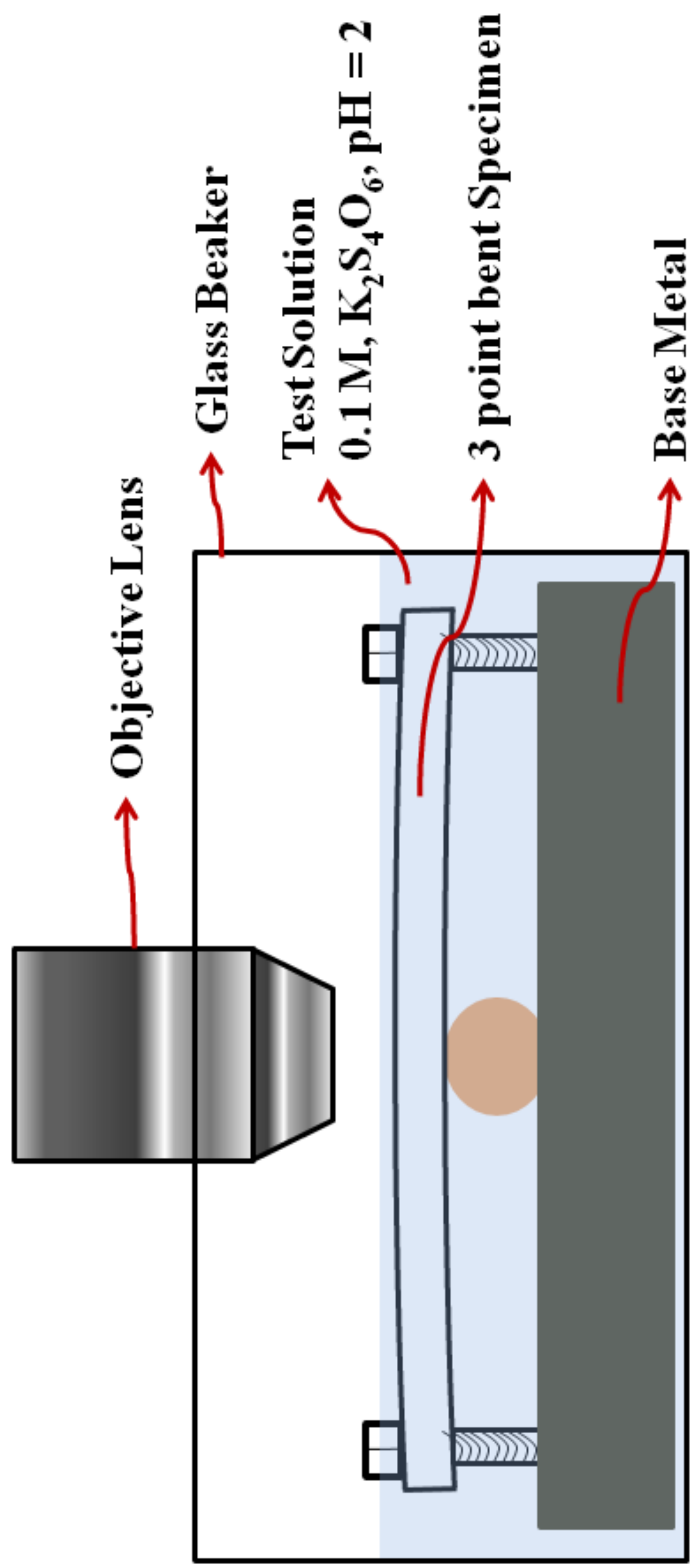



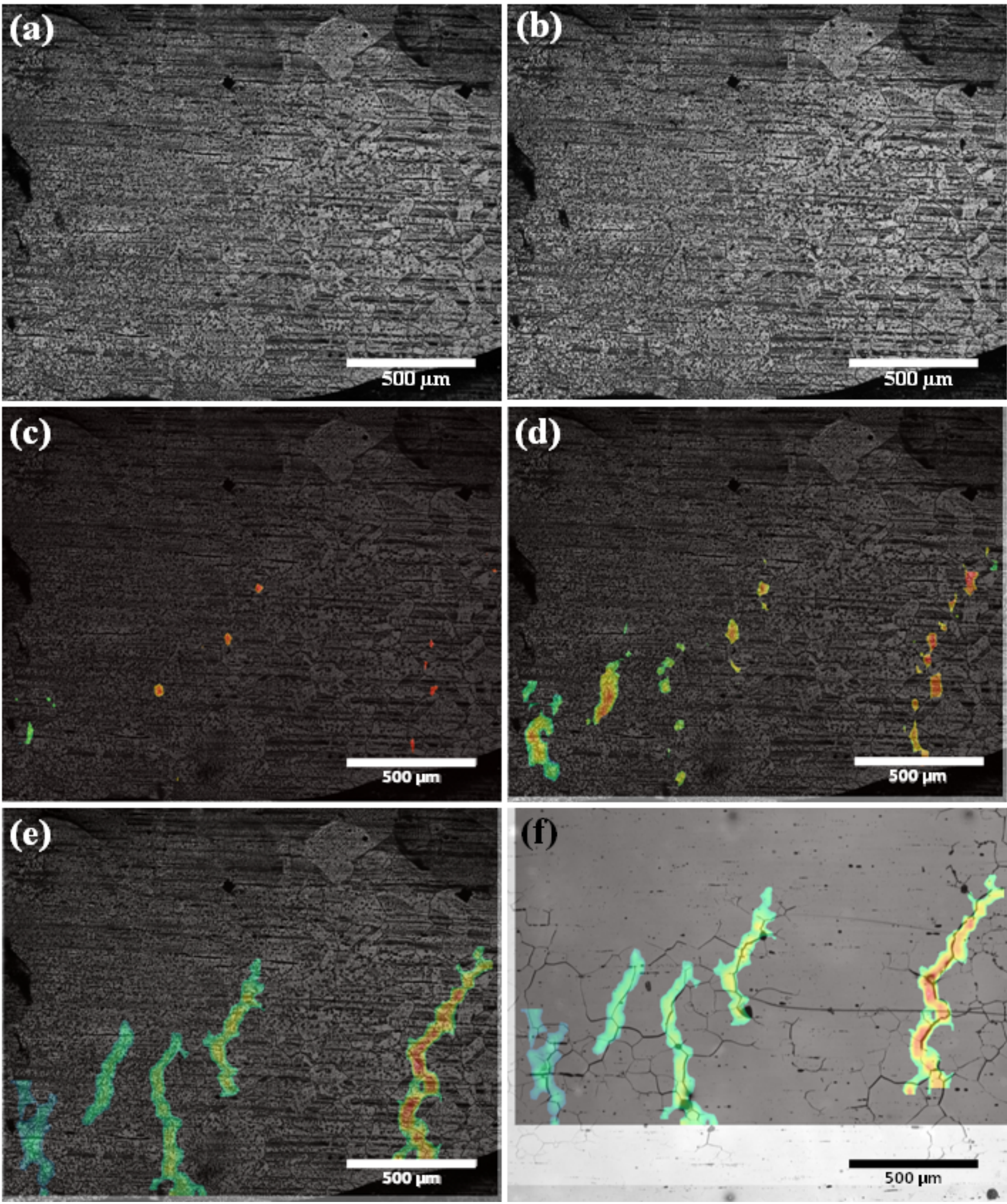

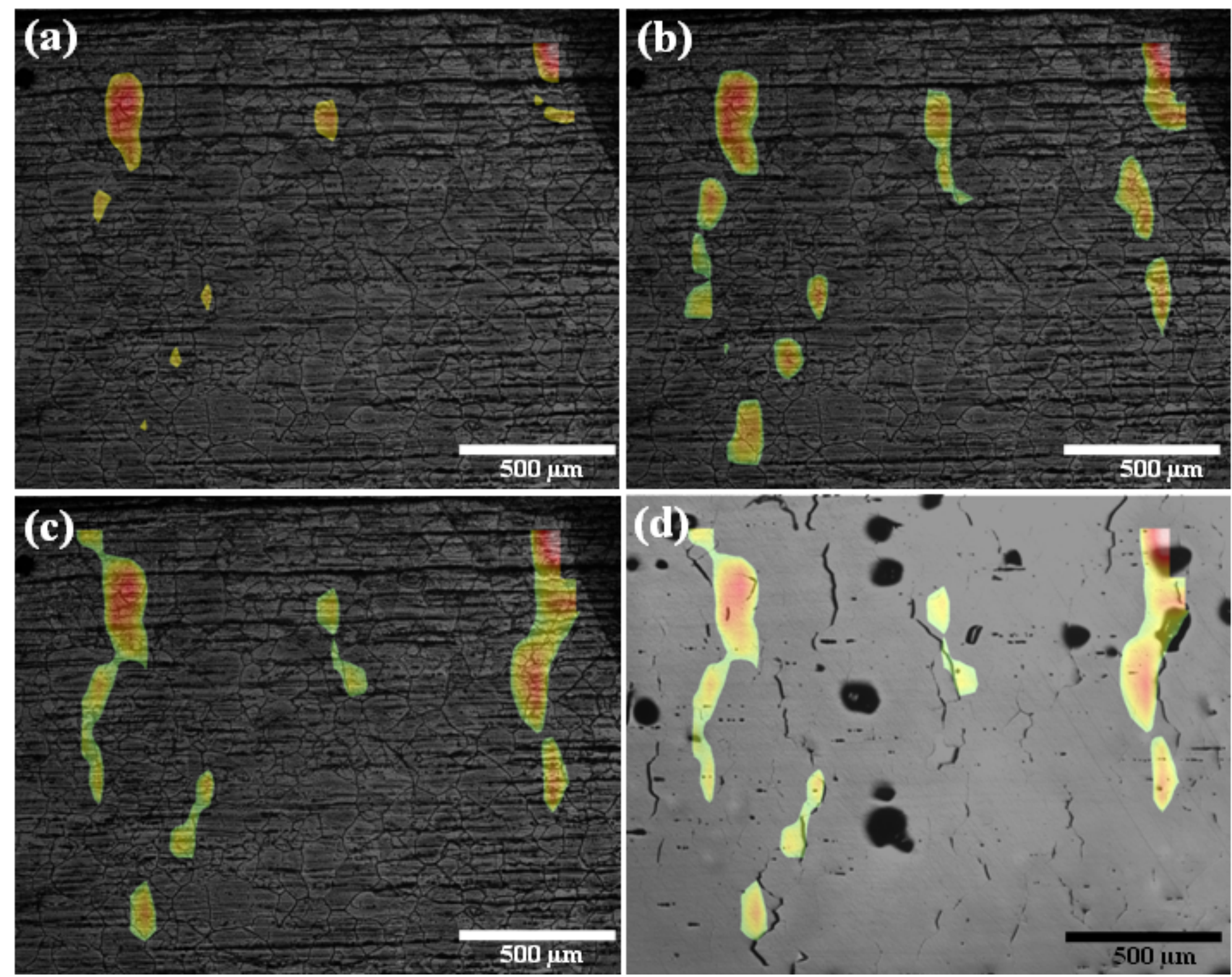


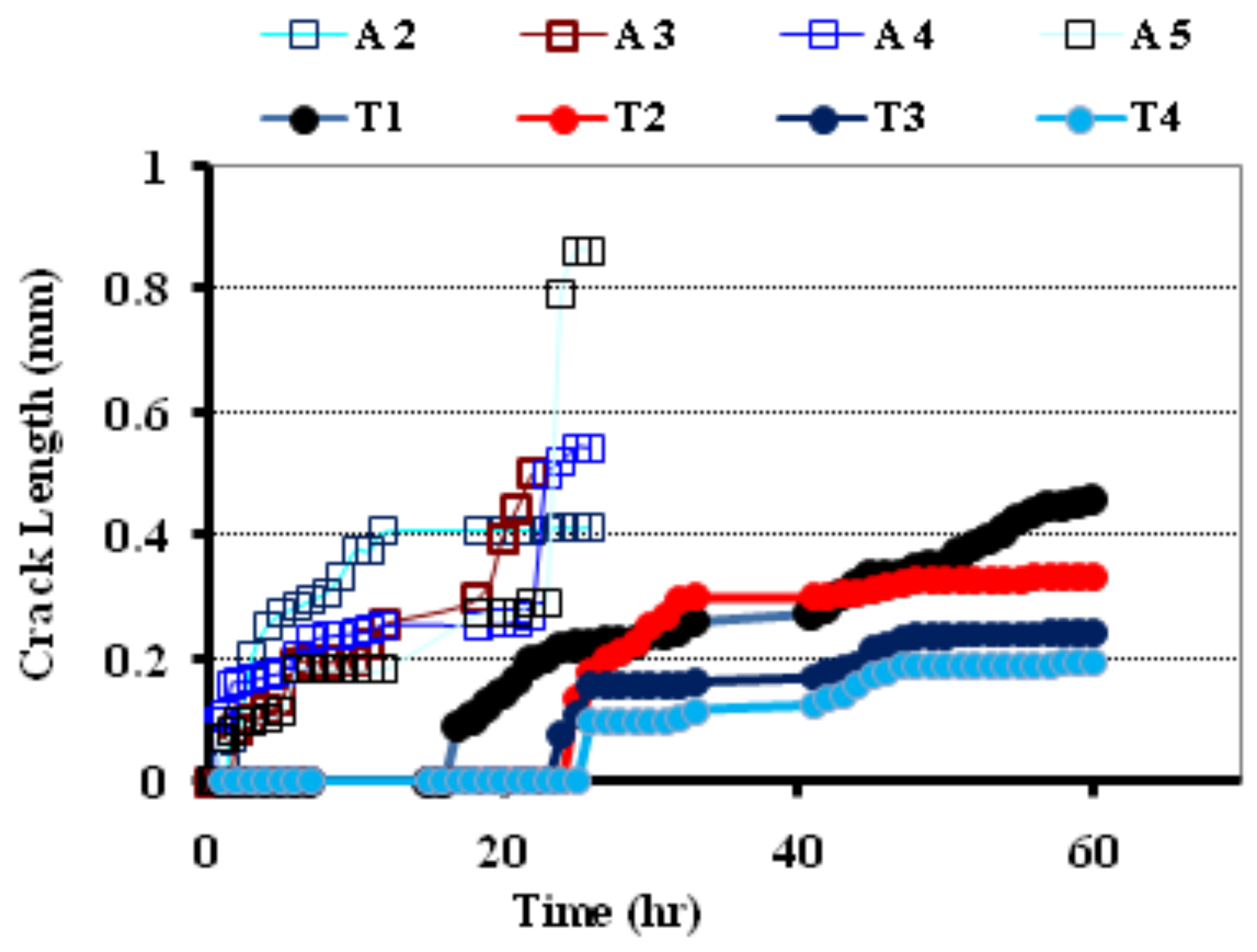



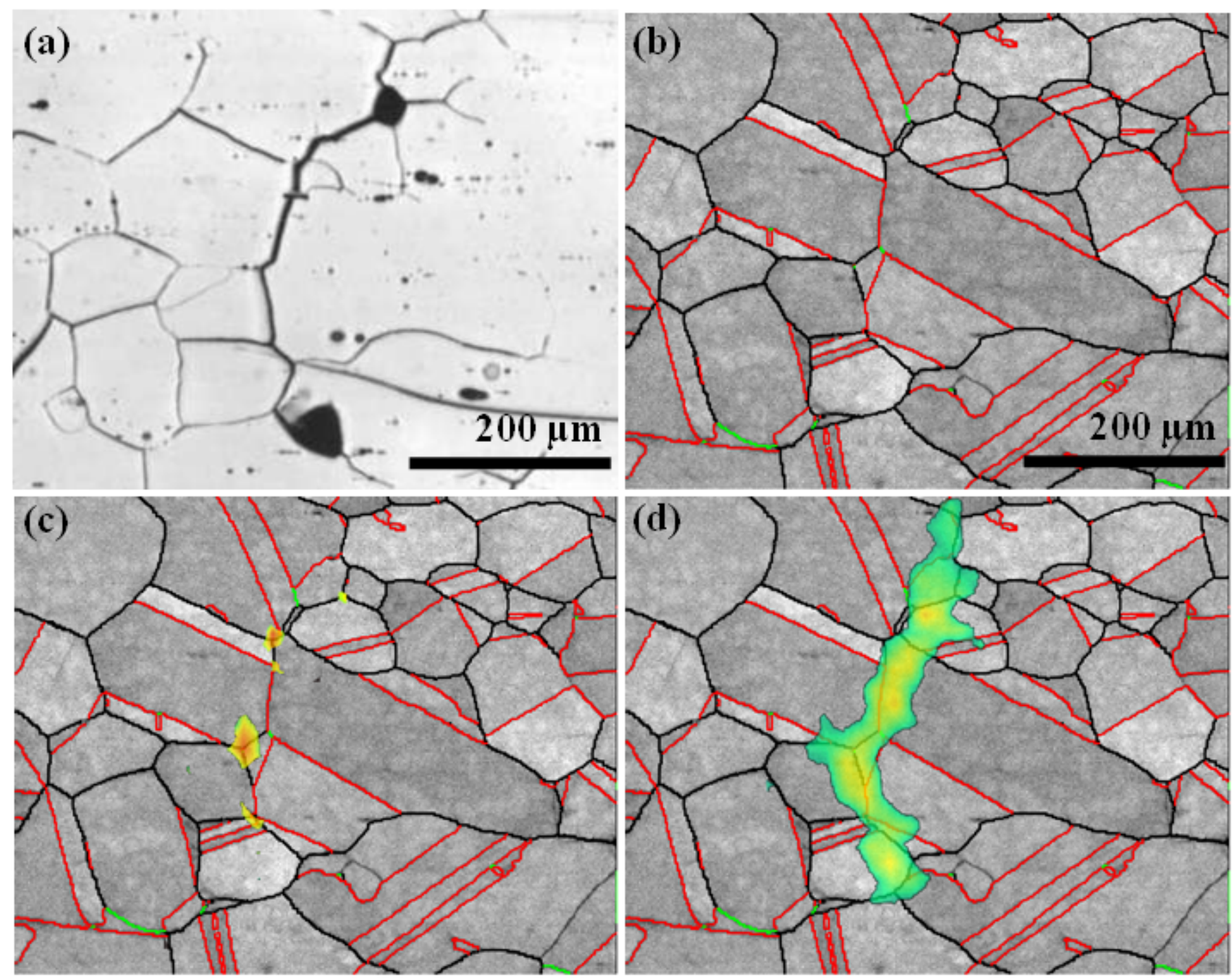


\section{$150 \mu \mathrm{mm}$}
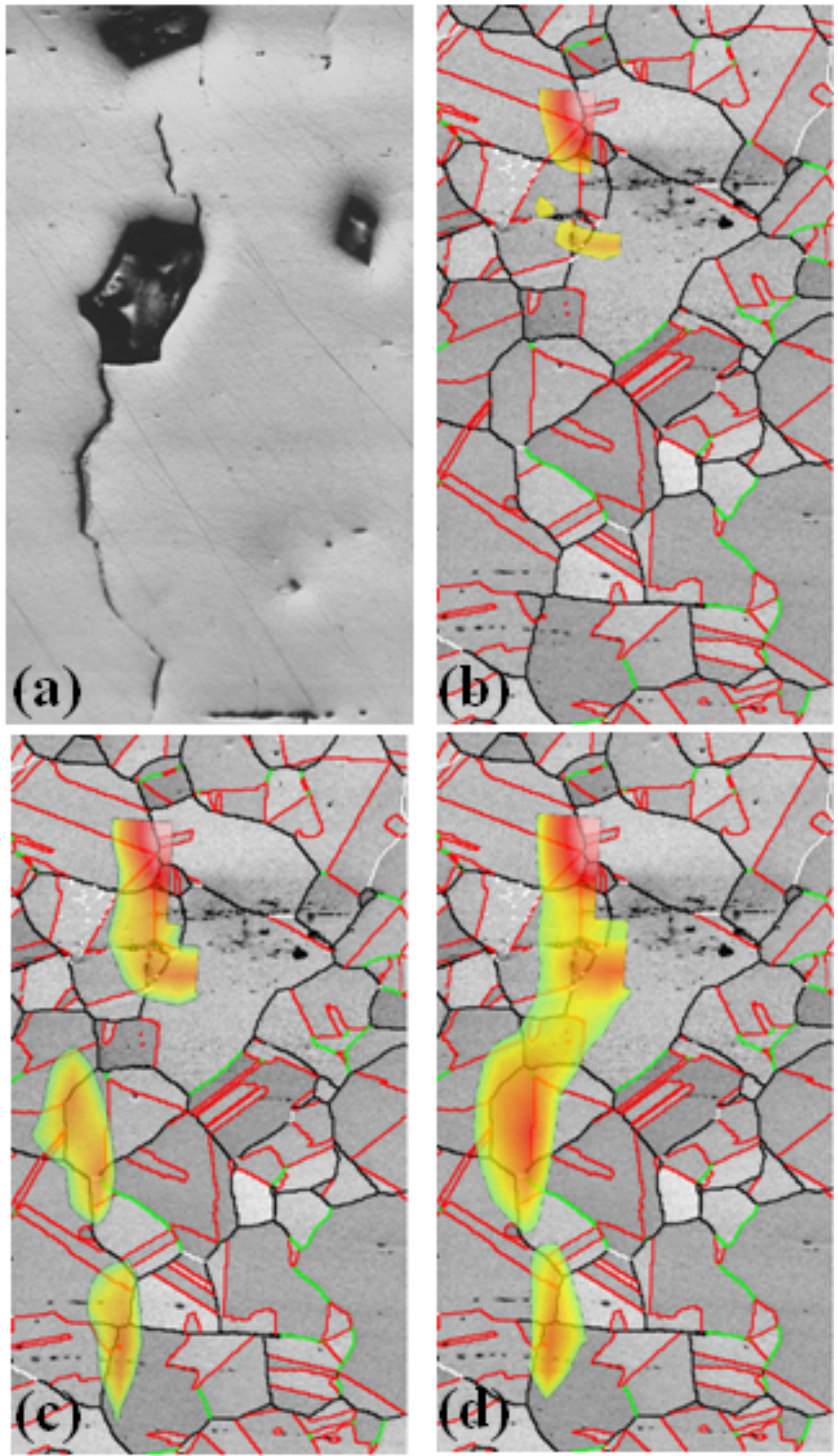


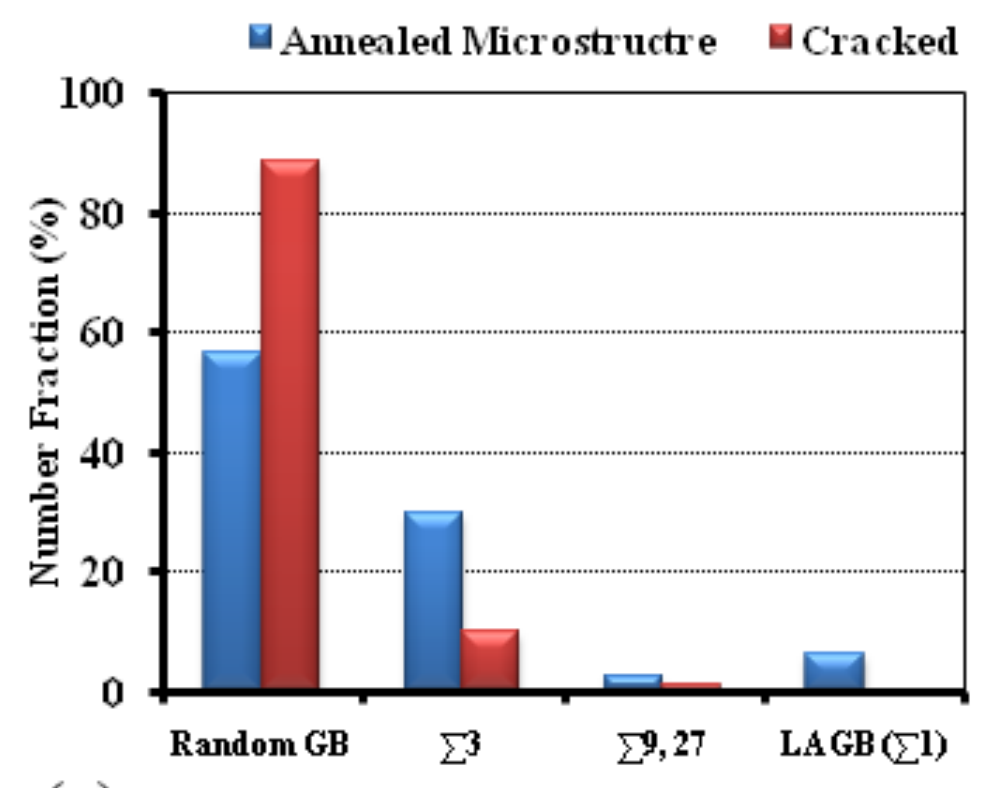

(a)

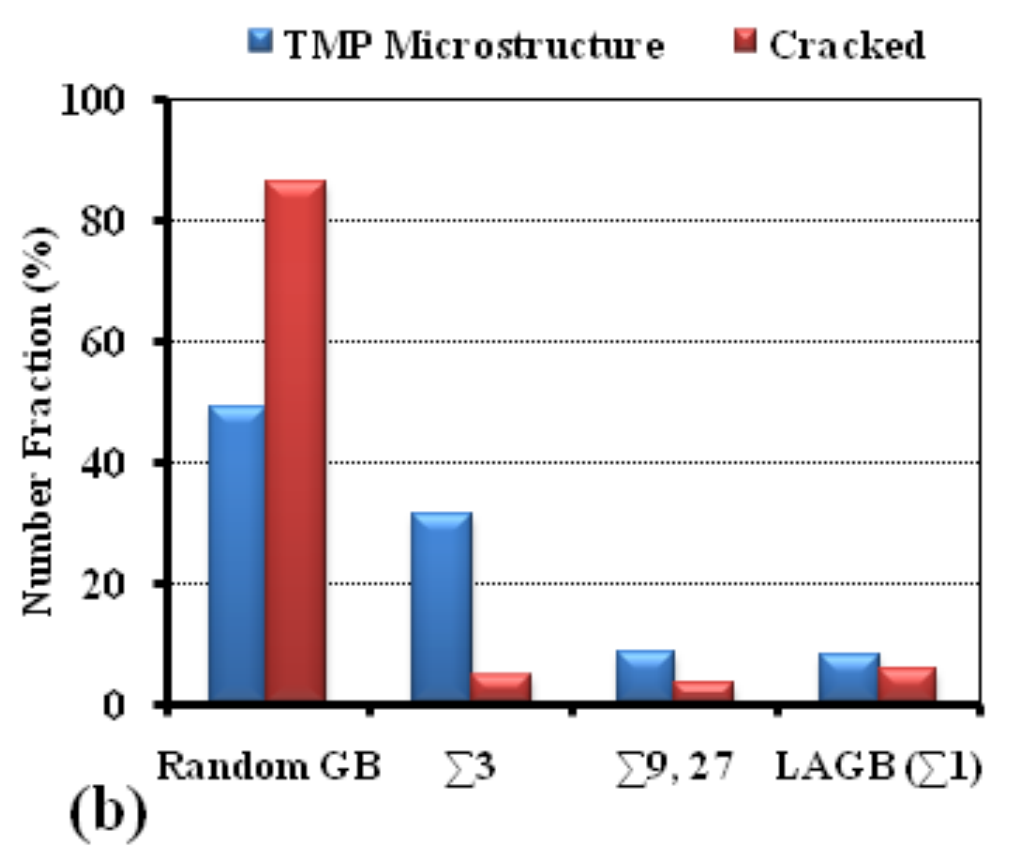




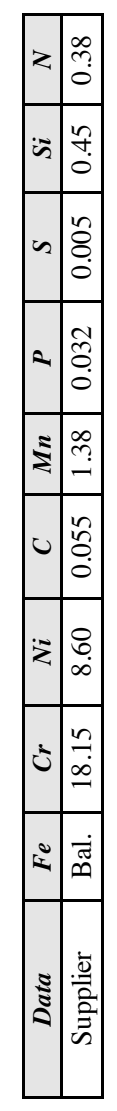





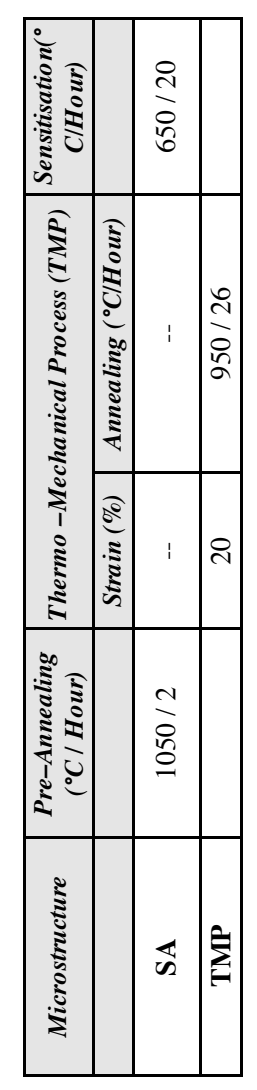





\begin{tabular}{|c|c|c|c|}
\hline \multirow{2}{*}{ 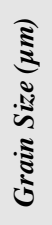 } & 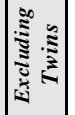 & $\begin{array}{l}\infty \\
+1 \\
n \\
n\end{array}$ & $\begin{array}{l}+ \\
+1 \\
n \\
i n\end{array}$ \\
\hline & $\mid$ & $\begin{array}{l}\frac{t}{+1} \\
i \\
i n\end{array}$ & $\begin{array}{l}a \\
+1 \\
b\end{array}$ \\
\hline \multirow{3}{*}{ 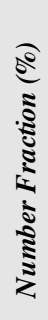 } & $\mid \begin{array}{c}\hat{a} \\
\hat{\omega}\end{array}$ & $\begin{array}{l}0 \\
\text { pin } \\
\text { d }\end{array}$ & $\begin{array}{c}\vec{y} \\
0 \\
\infty \\
\infty\end{array}$ \\
\hline & W & $\begin{array}{l}\text { in } \\
\text { i1 } \\
0 \\
0\end{array}$ & $\begin{array}{l}n \\
\text { ñ } \\
0 \\
\dot{m}\end{array}$ \\
\hline & $\mid \begin{array}{l}\overrightarrow{T_{1}} \\
v_{1} \\
\omega\end{array}$ & 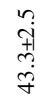 & 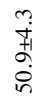 \\
\hline \multirow{3}{*}{ 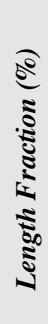 } & $\mid \begin{array}{l}\hat{y} \\
\hat{\omega}\end{array}$ & & 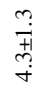 \\
\hline & m & 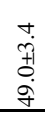 & 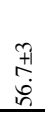 \\
\hline & 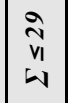 & 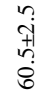 & $\begin{array}{l}\text { îं } \\
\text { t. } \\
\text { के }\end{array}$ \\
\hline 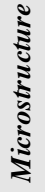 & & की & $\sum_{i=}^{\hat{z}}$ \\
\hline
\end{tabular}





\begin{tabular}{|c|c|c|c|}
\hline \multicolumn{4}{|c|}{ ไ్ำ } \\
\hline 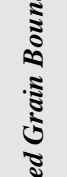 & 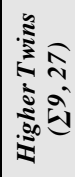 & $\stackrel{\simeq}{\longrightarrow}$ & $\stackrel{+}{\oplus}$ \\
\hline $\begin{array}{l}5 \\
5 \\
\delta \\
\Xi\end{array}$ & 言尊 & $\stackrel{\circ}{ }$ & $\stackrel{\circ}{+}$ \\
\hline है & 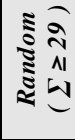 & 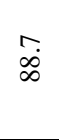 & గु) \\
\hline 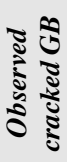 & & 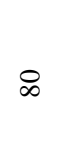 & $\bar{\infty}$ \\
\hline 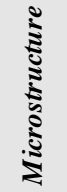 & & 出 & $\sum_{i=1}^{e}$ \\
\hline
\end{tabular}


